\title{
La medicina, los médicos y el P. Feijoo
}

\author{
por JULIO MORROS SARDA \\ Catedrático de la Universidad de Oviedo
}

Afirmar con excesiva pompa retórica - como alguien ha escritoque, a los doscientos años de la muerte del P. Feijoo, sus ideas científicas han quedado totalmente superadas, no es precisamente poner ninguna pica en Flandes de la crítica. Doscientos años son, natıralmente, muchos años; de modo especial, en el campo de la Medicina y de la investigación biológica. El avance extraordinario de las Ciencias en poco más de una centuria ha invalidado, por ley natural, muchas definiciones.

Pero, al reconsiderar la huella que han dejado los hombres que nos precedieron, hay algo que no es lícito echar en saco roto y que, a la postre, es lo que sirve para definir su valoración humana. Es, sencillamente, su ejemplo. La actitud que supieron adoptar frente a la "circunstancia» biográfica que les tocó vivir.

Benito Jerónimo Feijoo y Montenegro nació el 8 de octubre de 1676 y murió el 26 de septiembre de 1764. Natural de Casdemiro (provincia de Orense), vio la luz en caserío humilde, a unos pasos de la ciudad. 


\begin{abstract}
"Oasis dulce -escribe Marañón- que parece una isla encantada infinitamente distante del alma universal.» "Aún se conserva -continúa el ilustre doctor - en la casa señorial y blasonada por fuera, llana, casi humilde dentro, el cuarto en que el gran polígrafo naciera. Aún vive el gran pino, a cuya sombra transcurrió su niñez. Y allí está, inmutable en su maravillosa belleza, el paisaje verde y ondulado que contemplaron tantas veces los ojos del paladín español de la gran crisis intelectual del siglo xviII,»
\end{abstract}

Quizá para descubrir bien el espíritu del padre Feijoo hay que haber estado -como yo estuve- en el Monasterio Benedictino de San Julián de Samos, enclavado en el centro de la provincia de Lugo y donde, a los catorce años de edad y de manos de su abad, Fray Anselmo de la Peña, recibió el P. Feijoo la cogulla. Es allí, en aquel silencio de los jardines y ante el rumor de aquella fuente, donde se adivina el encuentro del espíritu amplio y abierto del P. Feijoo con el oscurantismo que reinaba en su época. Es allí donde comprendemos que un pensamiento como el del P. Feijoo, perfectamente encauzado, haya podido merecer elogios de Papas y de la altura de Benedicto XIV, del Cardenal Querini y de un gran número de literatos y sabios de primer orden, así como la estima de reyes, cual Fernando VI, que le concedió honores de Consejero del Reino, y de Carlos III, regalándole personalmente las «antiguiedades de Herculano»; es allí donde comprendemos que pudiese llegar, como llegó, a Maestro de su Orden con Prefecto de capítulo y haber sido tres veces abad.

Por muy superadas que hayan sido las definiciones formuladas por un antepasado nuestro, si estas definiciones sirven para dignificar el papel que le correspondió desempeñar, dichas definiciones tienen para nosotros plena vigencia en el momento de revisar su figura.

He aquí por qué nos parecen inadmisibles las conocidas palabras de Alberto Lista: "Al P. Feijoo se le debiera erigir una estatua y al pie de ella quemar sus escritos.» Palabras calificadas justamente por el doctor Marañón de "inconcebible tontería», frase que es hora de que se la califique de sandez.

Por el contrario, Joaquín de Entrambasaguas afirma que «tiene un ingenio indudable, no frecuente en el lenguaje serenamente gris de Lista». Y añade:

"Cuando Lista escribe esas palabras, la obra de Feijoo, casi por entero, ha perdido su eficiencia científica; su ideología, en gran parte, no agrada al crítico, como tampoco a muchísimos de nuestra época, y, en cambio, muestra intacta la gran labor cultural que realizó su autor, ya sólo de interés histórico, pues se ha superado por completo su nivel 
técnico; eríjasele, pues, un monumento por su trabajo y olvídese su obra. Y no se le dé una exactitud realista más allá de un ingenioso símil.»

Estas palabras de Entrambasaguas, escritas en 1942, y la confesión paladina de no agradar algunas de las teorías del P. Feijoo, ponen de relieve el escaso volumen crítico de tales afirmaciones. Y, de paso, nos muestran la facilidad con que se admiten como pasaportables algunas necedades por el solo hecho de tener apariencia de ingeniosas.

En lo que a nuestra especialidad se refiere - la Medicina-, nos basta la lectura de las muchas páginas que el P. Feijoo le dedicó para llegar a la conclusión de que, aunque quizá no nos agraden algunas de sus afirmaciones, merece la estatua solicitada por Alberto Lista -y que ya le han levantado sus admiradores, naturalmente--, y la merece, además, precisamente por sus escritos, que, aireados con motivo del bicentenario de su muerte, demuestran que no son ceniza todavía. Que es lo que pretendemos demostrar, cada uno en su campo específico, los que nos honramos en pertenecer a la misma Universidad a la cual perteneció el venerable Padre Maestro durante los mejores y más fecundos años de su larga vida, y desde la que vio irradiar al mundo entero la luz de su gloriosa personalidad.

Irradiación que le movió a escribir: "Veo volar glorioso mi nombre, no sólo por toda España, sino por casi todas las naciones de Europa.»

Pero, antes de seguir adelante en esta disertación, séame permitido un inciso para hacer constar que cualquier cosa que yo pueda decir del P. Feijoo ha de tomarse como sincera, pues ni mi personalidad de Médico, ni la de Catedrático, fueron precisamente aduladas por el Padre Feijoo.

De Médico, porque fuimos los médicos los que más fustigación recibimos de él, hasta tal punto que, cuando en su Teatro Crítico dedica un capítulo a la Policía de la senectud, decía que realmente lo que podía acreditar robustez es «que nunca le han visto consultar al médico ni usar cosa de botica como hacen los enfermizos», y, a continuación, con mucho gracejo, decía: «...pero que eso consistía en que sabía lo poco o lo nada que para lo que padeciese pudiese esperar de los médicos.»

Y como Catedrático, también tenemos un crítico en el P. Feijoo, que tanto fustigó la enseñanza, y de los que decía "que presumían de saber algo", y él mismo refiere algunos sucesos grotescos que dice haber pre- 
senciado, como el del catedrático que durante un año explicó sólo dos cuestiones, o del otro que murió de un ataque de apoplegía cansado por un argumento.

Pero claro es que no se pueden tomar en cuenta estas agresiones, no solamente porque no eran más que un módulo para su feliz crítica, sino porque, como Médicos y como Catedráticos, se ha de considerar al Padre Feijoo como compañero. Como Médico, porque, sin ser él médico, supuso mucho su personalidad en la Medicina de su época; y como Catedrático, buen compañero fue el P. Feijoo, que desde que en San Vicente de Oviedo, donde representó el cargo de Lector y recibió los grados de Licenciado y Doctor en Teología, fue siempre un Maestro. Y por oposición obtuvo el P. Feijoo la Cátedra de Teología Tomística, hasta que en el año 1739 le jubilaban; $\mathrm{y}$, estando ya jubilado el catedrático, era tal su poder de enseñanza, que el Consejo de Castilla pidió informe al Claustro sobre una solicitud suya para que se le diera permiso para hacer otra oposición. Y, en una palabra, son cuarenta años los que ocupó el P. Feijoo el sillón de Catedrático, y con tanta sapiencia, que, por mucha que fuese la diatriba contra nosotros, tendríamos que honrarnos llamándole compañero.

Nos dice Marañón en su libro Tiempo viejo y tiempo nuevo que sus obras - Teatro Crítico y las Cartas Eruditas- "obraron el milagro de sacudir los nervios atónicos de una humanidad que parecía extinguida para toda otra cosa que no fuera el simple vegetar».

"Su fama - sigue expresando Marañón- volaba por encima de los Pirineos y llegaba al resto de Europa, en cuyas Academias, llenas de la generosa pedantería de la Enciclopedia, se discutían las doctrinas audaces del escritor español... Y no sólo hacia Europa, sino también hacia América, a través del vasto mar, volaron, como una bandada de pájarus graciosos y disertos, los pensamientos de Feijoo."

Glorioso vuelo -nos atrevemos a afirmar desde nuestra modesta atalaya-, no por el acervo cultural que proporcionó a la Ciencia espanola, sino por su irreductible actitud de ir contra viento y marea de las opiniones que él consideraba equivocadas.

$\mathrm{Y}$ que lo era, efectivamente, en alto porcentaje desconsolador. Y no menos glorioso, aun en el caso de estar equivocado, por el valor, la entereza y la arrogante serenidad con que arremetía contra lo que él consideraba errores, haciéndolo a pesar de los contratiempos que tal actitud habría de acarrearle. 
En este sentido son dignas de admiración estas palabras suyas:

«Dijo bien el P. Malebranche -escribe en el prólogo del primer tomo de su Teatro Crítico- que aquellos autores que escriben para desterrar preocupaciones comunes no deben poner en duda que recibirá el público con desagrado sus libros. En caso que llegue a triunfar la verdad, camina con tan perezosos pasos la victoria, que el autor, mientras vive, sólo goza el vano consuelo de que pondrán la corona en su túmulo."

Creemos útil, para no caer en pecado de deformación profesional, dejar consignadas algunas generalidades aplicables a la totalidad de su obra, aplicables, naturalmente y de modo especial, al campo de sus teorias sobre la Medicina.

Cuanto pudiera decirse sobre las teorías médicas, ocurrió en la totalidad de la obra feijoniana. Y por esta razón, quizá, consigamos dar mejor impresión de cuanto a la Medicina se refiere, si lo incrustamos en el campo total de las obras de Feijoo. Sin perjuicio, como es lógico, de centrarnos más adelante en nuestro específico campo de la Medicina.

Las consecuencias de la posición intelectual del P. Feijoo fueron incalculables. Las resume con notable brillantez Millares Carlo, en el interesante prólogo de su Antología, publicada en la Colección de Clásicos Castellanos:

«Su constante esfuerzo - dice- sembró la semilla que, andando el tiempo, había de dar resultados tan beneficiosos como la fundación de la Academia de nobles artes de S. Fernando (1753); la reforma de los Colegios Mayores, defendida desde 1771 por Pérez Bayer y no implantada hasta 1777; la creación, en 1770, de los Reales estudios de San Isidro; la apertura, en 4 de noviembre de 1776, del Gabinete de Historia Natural dirigido por Bowles; y la inauguración, años después -1787-, de la primera Cátedra de Química del Reino, desempeñada por don Pedro Gutiérrez Bueno. Las enseñanzas filosóficas fueron gradualmente libertándose del yugo eclesiástico, y las Matemáticas, cultivadas con entusiasmo en los Colegios de Guardias Marinas, Artillería de Segovia -1764- y Escuelas Militares de Avila y Ocaña. El estudio detenido de la multitud de problemas, ideas y orientaciones, apuntadas por el autor del Teatro Crítico, nos hace comprender mejor las causas del resurgimiento cultural de nuestra Patria durante el reinado de Carlos III.»

De cual era la situación cultural de la España del siglo xviri hablan, con abundancia de datos, historiadores, polígrafos y críticos. Menéndez y Pelayo, en su apología de la Ciencia Española, estima, como es sabido, que el siglo XviII no vivió la decadencia científica, puesta de manifiesto por el P. Feijoo. «Ni Feijoo está solo - escribe el gran polígrafo montañés-, ni los resultados de su crítica son tan hondos como suele creer- 
se, ni estaba España, cuando él apareció, en el mísero estado de ignorancia, barbarie y fanatismo que tanto se pondera.» Otros escritores acompañan a Menéndez y Pelayo en tal opinión.

Ponderadas — como son habituales en él- son las palabras de Marañón, centrando debidamente esta cuestión:

«Podrán hallarse razones que justifiquen la decadencia política de España - escribe- al terminar la dinastía de los Austrias y comenzar la de los Borbones. Pero el espíritu más partidista no podrá negarla. Aquel final del reinado de Carlos II debió tener todas las apariencias de que era algo más profundo que la disolución de una dinastía; parecía un ensayo general del tin de España."

$\mathrm{Y}$ en otro lugar afirma:

«En el siglo xvirr, como en todo, hubo de todo: malo y bueno. Pero, aun teniendo en cuenta estas salvedades, estos altos y bajos en el nivel de la cultura y de la prosperidad general del país, es evidente que el contenido de la centuria, bien exprimido y estrujado, da muy poca sustancia a la gloria del genio español.»

Este reconocimiento de la decadencia española originaba lancetazos constantes en la sensibilidad del P. Feijoo. Y, en tanto, se esfuerza en Carta XVI (del tomo II de las mismas), titulada Causas del atraso que se padece en España, enumera las que, a su juicio, son las culpables de dicho atraso o estancamiento.

"Primera: Corto alcance de algunos de nuestra profesión. Segunda: Preocupación de España contra toda novedad. Tercera: Errar conceptos de que cuanto nos presentan los nuevos filósofos se reduce a unas curiosidades inútiles. Cuarta: La dominante o falsa noción que tienen acá muchos de la Filosofía moderna junto con la bien o mal fundada preocupación contra Descartes. Quinta: Es un celo, pío, sí, pero indiscreto y mal fundado, un vano temor de que las doctrinas nuevas, en materia de Filosofía, traigan algún perjuicio a la Religión. Sexta: La emulación (acaso se le podría dar otro nombre), ya personal, ya nacional, ya faccionaria. Si Vuestra Merced examinase los corazones de algunos, y no pocos de los que declaman contra la Nueva Filosofía, generalmente, por decirlo mejor, contra toda la literatura distinta de aquella común que ellos estudiaron en el Aula, hallaría en ellos unos defectos distintos de aquellos que suenan en sus labios. Oyeseles reprobarla, o ya como inútil, o ya como peligrosa. No es esto lo que pasa allá dentro. No la desprecian o aborrecen: la envidian. No les desplace aquella literatura, sino el objeto que brilla con ella,»

Es justo reconocer que la envoltura literaria, en cierto modo discretamente amable, encierra una tremenda acusación contra los estamentos intelectuales, acusándoles de refractarios a toda novedad $\mathbf{y}$, esto es peor aún, justificando la actitud en una deleznable envidia. 
En la Carta XXXI (tomo III de ellas) vuelve al mismo tema bajo el título de Adelantamiento de ciencias y artes en España. Aboga por la lectura, con esta queja amarga:

«Bastantes libros tenemos por acá en que ocupar agradablemente el tiempo. Si se habla de libros de comedias y novelas, bastantes hay. Pero esos libros son nocivos para muchas personas, especialmente para jóvenes de uno y otro sexo. Doy que no lo sean. ¿No será mejor sacar de la lectura, sobre el deleite de gozarla, alguna noticia Física, Astronómica, Botánica, Geográfica, de Historia Natural, etc., que es un bien algo estable y duradero, que el deleite solo de la lectura, que únicamente tiene la existencia pasajera de uno u otro rato?"

Nadie más indicado que el P. Feijoo para intentar el arreglo de tanto desaguisado cultural e intelectual. Fuerzas y cualidades no le faltaban...

Veamos -en una síntesis cinematográfica- cuál era la descripción intelectual de nuestro protagonista:

«Fue un hombre de inteligencia clarísima. Tuvo, gracias a Dios, como arma, un estilo de claridad sorprendente y fácil. Del primer rasgo de su pluma salen perfectos discursos. Nada escribe dos veces. Ni un ápice suele añadir a lo que una vez escribe.» (Fray José Pérez.)

Algunos autores atacan el estilo del P. Feijoo. Entre ellos, Menéndez y Pelayo, que escribe: «El coloso de la crítica no es un modelo acabado para que en él se formen los aprendices de las bellas letras.» Araujo Costa añade: "Feijoo escribe mal." "El lenguaje es peor -apostilla Lafuente en el prólogo de la Antología feijoniana»-, plagado de galicismos, latinismos e idiotismos particulares de las dos provincias donde pasó la vida, Asturias y Galicia.» Pi y Margall, por su parte, afirmó: "Como escritor se le suele estimar en poco.»

Entrambasaguas, por el contrario, escribe: «Qué sencilla flexibilidad y qué sello tan español en la expresión cortada, breve, enteramente actual.»Y añade: "Con fina percepción halla similitud Marañón entre el estilo de Feijoo y el de Azorín, considerando a aquél como el creador, en castellano, del lenguaje científico.»

El P. Flórez define: "Su estilo es de imposible emulación.»

Estimo, no obstante, que el P. Feijoo es quien tiene también el derecho de dar opinión sobre el estilo literario. Oigámosle a través del tomo I de sus Cartas Eruditas:

«Puede asegurarse que no llegan ni aun a una razonable medianía todos aquellos genios que se atan escrupulosamente a las reglas comu- 
nes, a Yo convendria muy bien con los que se atan servilmente a las reglas, siempre que no pretendan ajustar a los demás al mismo yugo. Ellos tienen justo motivo para hacerlo. La falta de talento les obliga a esa servidumbre. Los hombres de corto genio son como los niños de. la escuela que se arrojan a escribir sin pauta en borrones y garabatos desperdiciando la tinta. ¿Pureza de la lengua castellana? ¿Fureza? Antes se debería llamar pobreza, desnudez, miseria, sequedad.

Su intuición ante los problemas fue otra de las armas típicas del P. Feijoo, y así lo proclama Azorín: "Su intuición fina, delicada, suplía muchas veces la falta de materiales para realizar verdaderos milagros de erudición.»

Su afán por la lectura le sirvió para acumular un caudal inapreciable de conocimientos y de erudición.

"iQué cosa más dulce que estar tratando todos los días con los hombres más racionales y sabios que tuvieron los siglos todos, como se logra con el conocimiento de los libros!»

Y añade en el Desagravio de la profesión literaria:

"Si un hombre muy discreto y de algo singulares noticias nos da tanto placer con su conversación, ¿cuánto mayor le darán tantos como se encuentran en una biblioteca?» "Y, aunque es cierto que en muchas materias no se puede descubrir el fondo o apurar la verdad, en esas mismas se entretiene el entendimiento con la dulce golosina de ver los sutiles discursos con que la han buscado tantas mentes sublimes."

Con estas palabras pone de relieve y justifica su afán por la lectura de libros extranjeros, ya que, desgraciadamente, no podía saciar su curiosidad en la indígena bibliografía nacional, harto desmedrada.

«Despreciando el socorrido tópico de llamar infectos aires del Norte a toda extraña influencia - afirma Millares copiando al propio Feijoo-, recomendó con empeño ia lectura de libros extranjeros.»

Consecuencia inmediata de esta fecunda actividad no les fue difícil a sus miopes adversarios adjetivarle de «enciclopedista afrancesado». ¡ Lo de siempre, claro! Para no extendernos en esta problemática, considero viables las siguientes palabras de Vila Selma:

"Advertimos claramente en Feijoo que, tantas veces como se refiere a testimonios de autores extranjeros, franceses o no, lo hace no para asimilar y aceptar rendidamente el pensamiento foráneo, sino simple- 


\section{LA MEDICINA Y FEIJOO}

mente como lo hará siempre todo buscador de fundamentos con validez universal para su propio pensamiento. No es el afrancesamiento la clave del pensamiento feijoniano, sino la utilización de todo aquello que, francés o no, pueda enorgullecer a cualquier ciudadano de la república literaria.»

A todas estas sobresalientes condiciones añadía Feijoo, como colofón, un intenso hábito de trabajo.

"Transcurrió su vida -apunta Millares- dada por entero al estudio y sólo turbada por los ataques que le movieron la ignorancia y el despecho.»

\section{Y debió de tener un encanto en la conversación:}

«Los que tratamos al Padre Maestro - afirma Fray José Pérez- nos parece que cuando habla oímos hablar a un Cicerón. Habla con notable discreción, con exacta naturalidad y con igual propiedad; persuade Jo que dice con tanta eficacia, que todos asienten a lo que propone; es tal su gracia en el decir, que suspende y embelesa a quienes le oyen.»

Finalmente, y ésta es la clave de la cuestión feijoniana, tuvo, por la gracia de Dios, un instrumento de trabajo que fue origen, causa y motor de toda su vida de ensayista, polígrafo o enciclopedista (que de todas estas maneras ha sido calificado); tuvo arraigadísima en su clara mente la concepción del método experimental.

No aceptó Feijoo el criterio de autoridad, a las primeras de cambio:

«Por eminente que sea o haya sido la santidad de los escritores - escribe-, no por eso se ha de tener por cierto lo que hayan escrito. Será, por consiguiente, lícito apartarse de su sentir en una u otra cosa, cuando la razón nos persuade de lo contrario.» (VIII-I.)

"No pretendí yo -reafirma (VII-XIII)—, de lo que sobra y falta en la física, que no se lea en las escuelas la doctrina de Aristóteles..., sino que esa doctrina se dé purgada de tantas inútiles cuestiones, en quienes se consume buena parte del tiempo, que fuera mejor emplear en explorar más de cerca la naturaleza.»

"Sin duda - afirma Marañón-, su gran Biblia y guía en las Ciencias fueron las obras de Bacón...»Y más adelante: "Los actos más pequeños de la vida, como los más solemnes, estaban contrastados por su razonamiento experimental. Nada se decía o sucedía a su lado que no fuera sometido por el fraile, a ser posible, a una comprobación, a un contraste 
minucioso con la realidad." Y en otro lugar: "La profundidad del sistema experimental no nace, como creen algunos, de la complicación de las técnicas, sino de la disposición rigurosa de la mente.» $\mathrm{Y}$ esto, rigurosidad en la mente y en la aplicación de un método experimental, fueron condiciones fundamentales de la personalidad de Feijoo.

Este declara en su ensayo titulado La voz del pueblo: «El fundamento grande de mi sentir es la experiencia.»

A propósito de Bacón, y saliendo al paso de las acerbas críticas que se le hicieron por adoptar sus procedimientos lógicos, el P. Feijoo escribe: «Dejen a la gente ruda esa vulgar cantinela de despreciar cuanto hay de los herejes sólo porque lo son" (Cartas II-XIII). Bastaría esta cita, aireada hoy con todo honor, cuando Su Santidad Pablo VI proclama la necesidad de un sincero acercamiento con otras Iglesias, para comprobar la vigencia del ideario feijoniano.

Dibujada a grandes rasgos la condición humana del P. Feijoo, no es de extrañar la avidez de su curiosidad intelectual hacia todas las ramas del saber.

«Ningún aspecto de la actividad intelectual — afirma Millares- escapó a su curiosidad. Basta leer los epígrafes de los capítulos del Teatro Crítico Universal y de las Cartas eruditas, para advertir cómo no escapó a su discriminación ninguno de los aspectos de las Ciencias y las Letras, Filosofía, Historia, Matemáticas, Costumbres, Folklore, Ciencias Naturales, Medicina, Supersticiones..."

«Propugnó la reforma de la enseñanza - continúa Millares- en la totalidad de las materias que se enseñaban en la Universidad, de modo especial las Ciencias Matemáticas y Físico-Naturales, la Historia y la Medicina. Expone sus preferencias literarias, su ideal de justicia y perfeccionamiento de la sociedad y del individuo; su ponderado concepto del patriotismo, sus consejos para remediar el atraso de la agricultura.» "Pero - termina-, aún más que todo, admirable es la constancia con que combatió errores, no por absurdos menos arraigados."

Fácilmente se comprenderá la multitud de contradictores que le salieron al paso, perfecta y clarividentemente previstos por el propio Feijoo. Marañón los justifica con estas bellas palabras:

«Un grande hombre es siempre el vértice de otras actividades humanas que giran en torno suyo y que él recoge, vivifica y ordena. En torno a Feijoo vemos ir y venir muchos de estos colaboradores, ilustres, mediocres o desconocidos. Uno le daba material de libros; otro, ideas; 
otros, la contradicción, piedra áspera, de cuyo frote sale tantas veces la luz; otro, la crítica injusta, que no abate, sino reconforta, porque el ilustre enemigo es también un colaborador.»

Entrambasaguas, por su parte, escribe:

«No es de extrañar que el móvil fundamental de la obra feijoniana provocara dos posiciones antagónicas; la admiración fanática por parte de los convencidos o no incursos en los errores combatidos, y el odio implacable de los que a todo trance deseaban mantener una posición que, aun errónea, contribuía a su propia personalidad.» "A Feijoo — dice en otro lugar - se le ataca objetivamente, en sus comienzos..., pero luego ya, sistemáticamente, apenas surge una de sus obras, hasta convertirse su publicación y la crítica en una alterada agresión en que, justo es decirlo, casi siempre sale vencedor Feijoo.»

El propio Padre Maestro definió admirablemente, en varios pasajes, el alcance de los enconados ataques dirigidos a él:

"Sobre varios puntos pertenecientes a mis escritos he reconocido muy discordes o los gustos o los dictamentos de muchos de mis lectores; pero sobre ninguno, tanto y de tantos, como el de si debo responder o no a los autorcillos que me impugnan... Con algo de lectura, una errada inteligencia de lo que se lee y un poco de aquel entonamiento pedantesco que llamamos aire magistral, hay las prendas necesarias para llenar un libro de objeciones y reparos que encantasen a infinitos simples, mayormente cuando el intento es mantener aI vulgo, ya literato, ya meramente lego, en las erradas máximas que heredan de sus mayores.» (Tomo II, prólogo.)

\section{Y continúa el Padre Maestro:}

"A quienes no disculpo, aunque los perdono, es a aquellos que en sátiras anónimas vertieron su saña, sin más motivo que el ver celebrada mi obra. ¡Oh envidia!, monstruo de tan infelices ojos, que no el humo, sino la luz, te saca lágrimas.» "Yo te confieso, lector mío, que me parece muy cuerda aquella antigua máxima de hablar con los muchos y sentir con los pocos. Pero tanta cordura no se acuerda con mi sinceridad. Y veo, por otra parte, que el contemplar tanto a los necios es estrechar mucho la libertad de los entendidos.»

El P. Sarmiento fue quien vio claro en este devanar de contraopiniones alrededor del P. Feijoo. He aquí sus claras, contundentes y luminosas palabras:

«Mientras van y vienen respuestas, vamos sacando el real de plata a los que quisiesen leer este célebre certamen nacional. Y así, aunque los mirones no puedan contener la risa, les costará su dinero; y mientras, a sombra del Padre, todos sacamos para pollas,»

La envidia, la amistad sincera, el rencor, el mal estilo, la admiración 
sin límites, el despecho mal disimulado, florecen alrededor de la obra feijoniana como muestra inequívoca de la vitalidad extraordinaria de su autor. Y, de modo más concreto y con mayor virulencia, afloraron todos estos exabruptos alrededor de los temas de Medicina que, con especial predilección, planteó el P. Feijoo.

Sintió el P. Feijoo una inclinación total hacia la Medicina y sus problemas. "Médico frustrado" le llama Marañón.

«No cabe duda - añade- que el gran médico que hubiera sido, medio sofocado por los hábitos y la teología, reaparece a cada instante, en su vida oficial y privada, ocasionándole no pocos disgustos, pero también alguna de sus más hondas satisfacciones."

Su obra fundamental queda incluida en su Teatro Crítico, con 118 disertaciones o discursos, y las Cartas Eruditas, que contiene 163. Abarca los siguientes temas, ya anunciados anteriormente: Física, Matemáticas, Historia Natural, Astronomía y Geografía, Filosofía, Moral, Economía y Derecho Político, Literatura, Filología, Supersticiones y Medicina.

«En 39 de sus Discursos - especifica Marañón- la temática es exclusivamente médica; y a todo ello hay que añadir las publicaciones, aparte de la serie principal y las cartas, por intervenir en las polémicas que se suscitaron en torno a sus ideas médicas.»

He aquí, por vía de curiosidad, algunos de los títulos más sugestivos, alabados y discutidos: Medicina. Régimen para conservar la salud. El médico de sí mismo. Señales de muerte aparente. De lo que sobra y falta en la enseñanza de la Medicina. Paradojas médicas. Sobre los funestos errores de enterrar a los hombres antes de tiempo. Del remedio de la tranfusión sanguinea. Sobre la ignorancia de la causa de las enfermedades. De la charlatanería de algunos médicos advenedizos. Sobre la ciencia médica de los chinos, etc.

Es sintomático ya que la primera publicación en prosa del P. Feijoo tuviera relación con la Medicina. "Fue - afirma Millares- la Aprobación apologética del scepticismo médico, del doctor Martín Martínez, fechada en Oviedo en $1 .^{\circ}$ de septiembre de 1725 ", es decir, unos años antes de que apareciera el primer tomo del Teatro Crítico. Como es sabido, el doctor Marañón limita en su divulgado libro Ideas biológicas del P. Feijoo los méritos del doctor Martínez. En este punto concreto, disentimos del ilustre autor en cuanto a nuestro propósito se refiere. Nuestro principal objetivo es destacar la valoración humana del P. Feijoo en su medio ambiente, como ejemplario para las horas presentes. Posiblemente, Ma- 
rañón tenga sobradas razones; pero, para la debida valoración que pretendemos, tenemos que concretar el medio ambiente en que vivió el P. Feijoo. Y no hay ningún género de dudas que, considerado así, la figura del doctor Martínez era de capitalísima importancia. Este era doctor en Medicina y médico honorario de S. M., profesor de Anatomía, examinador del protomedicato, socio y presidente, a la sazón, de la Regia Sociedad de Sevilla. Por la fama que le rodeaba, llegaron a llamarle «El Aguila de la Ciencia».

«Era tal su pasión por la Anatomía -leemos en un folleto anónimo-, que personalmente hacía muchas disecciones en el anfiteatro del Hospital General de Madrid, a las que algunas veces asistió el Rey para admirar los grandes acontecimientos de su médico.»

Según otro de sus panegiristas,

«el doctor Martínez echó los cimientos del verdadero estudio de la Física, Medicina General y Anatomía en nuestra Patria, enseñando a tratar a los españoles en lengua materna con pureza y elegancia, que contrastaba con el fárrago de frases y sentencias latinas con que agobiaba a sus pacientes la docta comunidad de entonces.»

Es indudable que se trataba, por tanto, de una personalidad de primera fila, al que con tal dignidad podría llamar Feijoo «hombre de sutilísimo ingenio, sobradísimo juicio y admirable erudición». Publicó su obra el doctor Martínez, titulándola Medicina Scéptica y Cirugía moderna con un tratado de operaciones quirúrgicas.

Dado el virus crítico de la época, le salió al paso inmediatamente Bernardo López de Araujo y Azcárraga, con su Centinela médico-aristotélica. A guisa de curiosidad y para centrar, desde la atalaya de hoy el pintoresquismo de la época y justificar una vez más la razón de la actitud feijoniana, mencionamos el título general de dicha Centinela, que, a la letra, reza así:

«Centinela médico-aristotélica contra scépticos, en la cual se declara ser más segura y firme la doctrina que se enseña en las Universidades españolas y los graves inconvenientes que se siguen de la secta scépticophyrrónica.»

El P. Feijoo arremetió donosamente contra la tal Centinela..., ensalzando la labor del doctor Martínez.

Al año siguiente, al aparecer el primer tomo del Teatro Crítico Universal, no es de extrañar que el P. Feijoo solicitara un juicio crítico del doctor Martínez.

Y el doctor Martínez, después de muchos circunloquios respetuosos y 
frases de reverencia y amistad, hace un cumplido elogio de los varios Discursos que contiene el primer tomo. Pero al comentar el quinto Discurso, titulado Medicina, surge la discrepancia... Era el terreno en que podía sentirse con autoridad el doctor Martínez.

$\mathrm{Y}$ justamente de este Discurso $\mathrm{V}$ y las anteriores reacciones del doctor Martínez y la ulterior del P. Feijoo quisiera hacer yo la entraña de la presente disertación; porque de ese fluir de opiniones, su respetuosa manera de entablar diálogo, sin herir susceptibilidades, recordando constantemente que "lo cortés no quita a lo valiente», surge la máxima enseñanza que, a través de los siglos, nos ha legado el P. Feijoo: nos ha enseñado que el diálogo merece serlo cuando no se pierde el respeto al que dialoga con nosotros, cuando no se le envuelve en un fárrago de palabras despectivas, peyorativas o fustigantes, haciendo bueno el concepto de Menéndez Pelayo: "La misma censura, cuando es descocada y brutal, cínica y grosera, me parece un crimen de lesa humanidad.»

No pretendo hacer hincapié en las opiniones puramente médicas que se sustentan en este famoso Discurso V. Las purgas, las sangrías y otras técnicas, de evidente popularidad entonces, han periclitado. Como es lógico, porque doscientos años, como decíamos al principio, son muchos años; pero escribe Feijoo una serie de afirmaciones relacionadas con un tema concreto -El uso y abuso de los llamados específicos-, y otra serie de consideraciones acerca de lo que podríamos denominar Deontología médica, que me es grato seleccionar en este momento para considerar si a los doscientos años de ser escritos merecen algo más que la quema, simbólica o no, que preconizaba el un poco inflamable Alberto Lista.

\footnotetext{
«Para precaver desde luego toda equivocación debemos distinguir en la Medicina tres estados: estado de perfección, estado de imperfećción y estado de corrupción. El estado de perfección en la Medicina es el de la posibilidad, y posibilidad, a lo que yo entiendo, muy remota. Poca o ninguna esperanza hay de que los hombres lleguen a comprender (como se necesita) todas las enfermedades, ni averiguar sus remedios específicos, salvo sea por vía de revelación. Pero, por lo menos, hasta ahora, estamos bien distantes de esta dicha. El estado de imperfección es el que tiene la Medicina en el conocimiento y práctica de los médicos sabios. Y el de corrupción el que tiene en el error y abuso a los idiotas.»

"El arte médico, en la forma que lo poseen los profesores más sabios, aún está muy imperfecto. Pero esto es cosa hecha, pues ellos mismos lo confiesan. De poco serviría, para demostrar esta verdad, alegar autores de otros siglos, porque acaso me responderían que, después acá, se adelantó mucho la Medicina.»
} 


\section{LA MEDICINA I FEIjOO}

Pasa revista a la Historia de la Medicina. "Todo en la Medicina es disputado, luego todo es dudoso."

«Fue criada la Medicina - arguye- como niña expósita, porque no había otra regla para curar a los enfermos que exponerlos en las plazas y calles públicas, para que los que transitaban les prescribiesen sus remedios, en que precisamente había infinita diversidad de pareceres, hasta que Hipócrates la tomó por su cuenta para darle leche en la pequeña isla de Cos, donde el perpetuo embate de las aguas pudo sèr nuevo presagio de la interminable lucha de opiniones.»

Llama a Galeno «verdaderamente tiránico, por la mucha sangre que derramó a todo el linaje humano, este gran patrono de la lanceta.»

"...Asi se iban variando los sistemas y destruyéndose unos a otros, cuando, o el tedio de tantos o la incertidumbre de ellos, hizo tomar a los médicos más advertidos otro rumbo, que fue buscar la naturaleza en sí misma fiándose a la experiencia sola. Es verdad que, desde que el gran Bacón de Verulamio abrió los ojos a los médicos y filósofos, dándoles a conocer que sólo por este camino podían adelantar algo en las dos facultades, no faltaron algunos médicos cuerdos que dieron hacia la experiencia algunas ojeadas y con este cuidado recogieron algunas observaciones, aunque, por la mayor parte, defectuosas...»

a...Culpa, ciertamente grave, de los escritores es engañar al público con la ostentación de remedios que ellos mismos experimentaron inútiles y exponer a los pobres médicos que estudian sus obras a la curación y al pronóstico, para quedar burlados, después de gastar con varias medicinas el caudal de la complexión de los enfermos.s

«Está bien visible la candidez de los españoles que, en viendo acá un médico francés de los que allá tienen mediana reputación, piensan que han logrado un hombre capaz de revocar almas del otro mundo.n

«...Es tan común en los médicos de mayor estudio y habilidad confesar la debilidad de su arte para expugnar las enfermedades, como en los más inhábiles ostentar gran confianza en ella para triunfar de estos enemigos.»

«...Los médicos ordinarios... que, si leen otros autores, usurn de ellos, no para curar, sino para hablar.»

«...En tanta discordia de los médicos, ya por la oposición de los autores, ya por la diferente inteligencia de ellos, ya por las diversas observaciones y juicios de los indicados, ¿qué hará el pobre enfermo? ¿Llamará, si tiene en que escoger, al médico más sabio? Muchas veces no sabrá quién es éste. El aplauso común frecuentemente engaña, porque suele tener más parte en el artificio y la política que la ciencia. Una casualidad pone en crédito a un ignorante, y una desgracia sola desautoriza a un docto."

«De cualquier modo que trate el médico a los enfermos, si no les da veneno, viven unos y mueren otros. El que está a favor del remedio 
aplicado atribuye la salud al remedio, si el enfermo vive, y la muerte, a la fuerza insuperable de la enfermedad, si muere; y la salud, a la valentía de la naturaleza, si vive. Por esta causa, muchas veces achacan injustamente al médico la muerte del dolientc y muchas le agradecen sin razón la mejoría. Lo cierto es que muchas veces vivirá y mejorará el enfermo no sólo ordenándole el médico una sangría fuera de propósito, mas también aunque le dé una puñalada, porque con todo puede su complexión."

«Los remedios costosos y raros son del gusto de muchos médicos y del de todos los boticarios.

"Lo mismo digo de los remedios exóticos que vienen de lejanas tierras. En ellos tienen su asiento los médicos para la ostentación de su arte y los droguistas para aumento de su caudal.

»Aun los específicos más notorios no están exentos de ser cuestionados.

»A esta inconstancia de la Medicina por la oposición de dictámenes se añade lo que alteran las modas, las cuales no tienen menos imperio sobre el arte de curar que sobre el modo de vestir. Al paso que van cobrando unos medicamentos, lo van perdiendo otros, y a la Medicina le sucede con los remedios que propone lo que a Alejandro con los Reinos que conquistaba, que al paso que adelantaba sus empresas iba perdiendo mucho de lo que dejaba a las espaldas.

"Todos los remedios en su primera composición fueron celebraditsimos; de aquí vienen aquellos epítetos magníficos que establecieron como renombres suyos: agua angélica, sal de Inglaterra, etc.

"En esta infame práctica menos influyen los médicos que los mis. mos enfermos. El vulgo tiene por medio sabio a aquel que sin cesar amontona medicamentos sobre medicamentos; y aun después que con este tirano y homicida procedimiento llevó al enfermo a la sepultura dicen que hizo cuanto cabía en el arte de la Medicina, siendo así que hizo cuanto sabía, en la más estúpida ignorancia o en la más criminal condescendencia.

"Sé que hay algunos $-\mathrm{y}$ no pocos- que recetan más de lo que les dicta la razón a fin de conservar su crédito; porque ven que los desestiman y llaman a otros si cada día no ordenan algo nuevo."

"Muchos toman un camino medio, que es recetar para cumplir; esto es, ordenar unas cosillas leves, que, aunque no harán provecho, tampoco se teme de ellas daño alguno; pero, si lo que ordenan está dentro de la clase de medicamentos, no puede menos de alterar, y, por consiguiente, si no aprovecha, forzosamente ha de dañar, poco o mucho.

»A los médicos doctos y acreditados de tales... no les llamará a cada paso ni la melisendra que todas las horas quisiera que la estuviese tomando el doctor el pulso, ni el maníaco por naturaleza, enfermo imaginario, como el de Molière, que está dando gritos cuando no le duele nada; ni el viejo decrépito, que juzga que pueden alejarle 
muchas leguas de la sepultura las drogas de la botica. Con esto tendrín más tiempo para estudiar y para reflexionar sobre lo que estudian y lo que experimentan, como también para asistir a las disecciones anatómicas; los más eminentes estarán más desocupados para escribir libros. De esta suerte, los médicos se harán más doctos y la Medicina irá dando cada día, hacia la perfección de que es capaz, algunos pasos."

En este famosísimo Discurso $\mathrm{V}$ enumera las condiciones indispensables en todo médico que se precie de tal. A saber:

«Que sea buen cristiano, que sea juicioso y de temperamento no muy ígneo; que no sea jactancioso en ostentar el poder y la seguridad de su arte; que no sea adicto a sistema alguno filosófico; que no sea amontonador de remedios, especialmente mayores, salvo en caso de urgencia apretadísima que no conceda tregua alguna; que observe y se informe exactamente de las señales de las enfermedades, que son muchas y se toman de muy varias fuentes; y, finalmente, que correspondan por lo común los sucesos a sus pronósticos.»

Termina de la siguiente manera el famosísimo Discurso V:

«Es notable la falta de cirujanos que hay en España; to cual, sin duda, depende de la poca estimación y salario que tienen. Aun los pocos que hay buenos, son de una extensión muy limitada en orden a las partes de que consta la facultad. De cuantos cirujanos españoles he conocido, sólo uno vi que fuese algebrista, y es cosa notable que, siendo $\tan$ frecuentes las fracturas, luxaciones y dislocaciones, al que padece algo de esto le hacen recurrir a tal o cual hombre de campo, que dicen tienen esa gracia curativa, siendo así que son ignorantísimos tales curanderos, como ya varias veces he visto y palpado. Uno de ellos, muy acreditado en el país donde vivía, siendo llamado de mí para curarme una pequeña luxación en un pie, me hizo estar tres meses cabales en la cama y otro mes andar con gran tiento arrimado a un bastón.»

La contestación del doctor Martín Martínez, al fin y al cábo profesional de la Medicina, fue correcta y respetuosa como quien correspondía a quien acababa de ser defendido entusiásticamente por el P. Feijoo. Pero, aun admitiendo, en general, las afirmaciones de éste, le propinó un claro palmetazo al comentar algunas de las exageraciones del genial benedictino.

«...Mándame Vuestra Reverendísima decir mi parecer sobre el I tomo del Teatro Crítico Universal, y, siendo imprescindible su precepto y mi obediencia, no he tenido poco quehacer en saber desnudarme del sublime concepto y apasionada veneración con que miro cualquier escrito de Vuestra Reverendísima...

"...Es de temer que la vehemencia de su retórica, queriendo apartar al vulgo del extremo de la confianza, lo haga pasar al opuesto extremo del desprecio y de la desesperación. 
"...Vuestra Reverendísima se muestra tan rígido que, por precepto superior, me es preciso proponerle algunos reparos con la mayor humildad.

»...¿En qué profesión se necesita más penosa y extendida lectura para instruirse? ¿Más perspicacia de sentidos y viveza del ingenio para ajustar prontamente las combinaciones? ¿Más solidez de juicio y nervio de prudencia para profesar materia tan circunspecta, en que se trata de la vida de los hombres y que la ocasión es precipitada? ¿Más refinada política para saberse conducir con tan varios estados, genios, costumbres y aprehensiones de gentes? ¿Más enfadosos trabajos para estudiar sobre cadáveres y asquerosos hechos? $Y$, en fin, ¿qué facultad hay más meritoria, por más expuesta a sustos, tristezas, incomodidades, riesgos y calumnias?

"...Culpo al fárrago de medicamentos; pero alabo al uso de los bien indicados...

"...Confieso la ignorancia de las causas morbíficas; pero admiro los caracteres por donde experimentalmente se distinguen y curan.

"...Aplaudo las racionales experiencias e indicaciones que pueden contribuir a establecer un sistema fundado en la naturaleza misma...»

\section{En cuanto a las condiciones del médico, el doctor Martínez contesta donosamente :}

"A que el médico sea buen cristiano, es difícil hacer los informes y aún más difícil averiguar las hipocresías.

"A que sea juicioso y de temperamento no muy ígneo, el vulgo suele tener por juicio lo que es simpleza y estolidez; y en todo hay riesgo, porque cuando el médico debe ser pegaso no se le ha de buscar tortuga.

"A que no sea jactancioso, mejor sería que sus aciertos los contasen Ios vecinos.

"A que el médico no sea adicto a sistema filosófico alguno, el pueblo no entiende de sistemas ni filosofía.

"A que el médico no sea amontonador de remedios, emplea su elocuencia en conseguirlo y no queda otro consuelo a los parientes que el que no ha habido cosa que no se haya hecho.

"A que el médico observe y se informe exactamente de las señales de la enfermedad, que son muchas y se toman de muy variadas fuentes, el que haya de ser fiscal en esto, debe primero saberlas todas.»

A las ponderadas objeciones del doctor Martínez contestó el P. Feijoo en tono mesurado: "Creo que estamos en un mismo pensamiento.» $\mathrm{Y}$, tesonero en sus puntos de vista, añadió: 
«Un engaño perniciosísimo, si dos engaños en uno padece el vulgo en el concepto que hacen de los médicos. Tienen por médico docto el arrogante y operativo; y, al contrario, por ignorante al que duda mucho y obra poco. Todo es al revés. El que más ha estudiado, es el que más duda; y el que más duda es el que menos obra.

"Otra vez lo digo: De aquel médico que desconfíe de su arte es de quien debe confiar el enfermo. La confusión sincera de la incertidumbre es el carácter que distingue al médico sabio del charlatán temerario. ¡Oh error fatal! Que si el médico no receta siempre que visita, juzga el enfermo que es porque sabe menos que el otro, que apenas suelta la pluma de la mano. Tan al contrario es, que ésté receta mur cho porque estudia poco y aquél receta poco porque estudia mucho."

Fácilmente se explicará que el estilo de nuestro Padre Maestro levantará una inmediata y cegadora polvareda de comentarios. Como cerezas se encadenaron comentarios favorables e invectivas tronitonantes; comentarios de los comentarios, contracomentarios de los recomentarios, que hicieron válidas las cáusticas palabras del P. Sarmiento, citadas con anterioridad.

Millares enumera las obras surgidas al calor de las controversias feijonianas. Sin dejar exhausta la fuente, cita ciento quince títulos, de los cuales cuarenta se refieren a problemas específicamente médicos. Los discursos titulados Medicina, Régimen para conservar la salud, Desagravio de la profesión literaria, fueron manjar especialmente dilecto para los contradictores.

En esta madeja de réplicas y contrarréplicas, en las que se empieza a hablar de Medicina y andan en danza la Astrología y las artes adivinatorias, aparecen, entre otros muchos, en la palestra: Aquenza, Diego de Torres Villarroel, Suárez de Ribera, García de la Rosa, Juan Martín de Lesaca, Carlos de Montoya, Francisco de Soto Marne, con el que sostuvo larga y porfiada pelea que cortó por lo sano el rey Fernando VI, para impedir que padeciera el prestigio universitario respetado del P. Feijoo.

Este, por regla general, sabía mantenerse en una posición comprensiva, como ya dijimos antes, y que ratificamos con estas nuevas palabras suyas :

"Bien sé que no hay más rígido censor de un libro que aquel que no tiene habilidad para dictar una carta. En ese caso, di de mí mismo lo que quieras. Trata a mis opiniones de descabelladas por peregrinas, y convengamos los dos en que tú me tengas a mí por extravagante; yo a ti, por rudo."

De la honesta intención de sus escritos afirma: 
JULIO MORROS SARDA

«Proponer y probar opiniones singulares, sólo por ostentar ingenio, téngolo por prurito pueril y falsedad indigna de todo hombre de bien. En una conversación se puede tolerar por pasatiempo; en un escrito es engañar al público.»

Y más adelante:

"Estoy esperando muchas impugnaciones, especialmente sobre dos o tres Discursos de este libro; y aun algunos me previenen que cargarán sobre mí injurias y dicterios. En ese caso, me aseguraré más de la verdad de lo que escribo, pues es cierto que desconfía de sus fuerzas quien contra mí se aprovecha de armas vedadas. Si me opusieran razones, responderé a ellas. Si chocarrerías y dicterios, desde luego me doy por concluido, porque en ese género de disputas jamás se ejercitará...

En verdad que no fue siempre consecuente con esas dignas palabras.

Salvador José Mañer empezó a publicar en 1729 el Antiteatro Crítico, refutando con orden, sin saña y no pocas veces con acierto, las afirmaciones del P. Feijoo. Este, en cambio, sacó la caja de los truenos, quizá cuando menos razón había. «En esta apología - la que él escribía para defenderse de los ataques de Mañer- se verá que el Antiteatro no es más que una trampa de teatro. Una quimera crítica; una comedia de ocho ingenios; una ilusión de inocentes; un coco de párvulos; una fábrica en el aire, sin fundamento, verdad ni razón.»

Y en cuanto al autor, después de declarar que nadie le conocía, añade :

"Otro me avisaba que conocía a dicho Mañer; pero le conocía por un pobre Zoilo, que nada había hecho ni podría hacer otra cosa que morder escritos ajenos; recurso fácil y trivial para que en el concepto de ignorantes hayan representación de escritores aquellos a quien Dios negó los talentos necesarios para serlo.»

Contestó Mañer, sin perder los papeles ni el respeto, que había encontrado 998 errores en las afirmaciones de Feijoo; y le fue contestado que "él había cometido 400 descuidos y que, de los 70 errores de Feijoo que al parecer quedaban en pie, se le rebajaban 69 y medio...»

Y no hacemos referencia a la citada publicación de la controversia con Soto Marne, porque abarca otros campos que el de la Medicina...

Amante de las cosas de España, contrariamente a lo que opinan los enemigos de Feijoo, figura a su lado la casi borrosa figura del médico gerundense Gaspar Casal, que ha merecido los honores del más encendido elogio por parte de Marañón. Gaspar Casal, según explica el ilustre doctor, "tuvo la suerte de no ser universitario. Si lo hubiera sido, su 
innata capacidad para la observación se habría ahogado en el ambiente estúpidamente teórico de las aulas, como sin duda ocurrió con muchos otros hombres bien dotados de su tiempo.»

«Con licencia obtenida en el Colegio de Sigüenza, donde, si no se enseñaba nada, por lo menos no convertían a los muchachos en pedantes incapaces de sacramento, licencia casi de sacamuelas, se lanzó Casal al ejercicio de la profesión por los pueblos de la Alcarria y de Soria..."

Es más seguro que nuestro gran médico no hubiera pasado nunca de practicón discreto, de fama pueblerina, a no haberle llevado su buena suerte a Oviedo, donde había de conocer al P. Feijoo, que le llama «mi estimadísimo amigo el doctor don Gaspar Casal».

«No hay muchos documentos que demuestren la colaboración de Feijoo en la obra única y magna de Casal en su Historia Natural y Médica del Principado de Asturias, en la que hizo la maravillosa descripción de la pelagra o mal de rosa. Pero nadie que sena a fondo la profunda sugestión que el benedictino ejercía sobre sus amigos, podrá ponerla en duda. Conocemos, no obstante, la carta que cita Roel en la que Feijoo advierte a Casal la existencia de la pelagra, no sólo en Asturias, sino también en Galicia, donde él la había observado con frecuencia. Y Casal, por su parte, refiere en su libro que, en efecto, se reunía con Feijoo y otros contertulios, en la celda de San Vicente, y comentaban y discutían la lectura de las últimas novedades médicas que enviaban al fraile sus corresponsales de Madrid o de Francia. Toda la obra de Casal está, sin duda, escrita bajo la tácita aprobación de su amigo el religioso. Y hasta en los momentos en que discrepa de él, como ocurre en muchos puñtos de la interpretación de las doctrinas hipocráticas, se trasluce que la pluma de Casal camina con tiento por no herir la susceptibilidad de Feijoo, que era, a veces, exagerada y, hay que decirlo, un tanto impertinente.»

Resultan sugestivos los conceptos de Marañón al ensalzar la actitud de discreto silencio con que Casal asimiló las preferencias experimentales preconizadas por Feijoo. El recato de la palabra ponderada, su ausencia en las fogosas y artificiosas polémicas, típicas de la época, convierten al médico Casal en una figura de singular valoración humana en la «circunstancia» vital en que vive Feijoo...

Echa por los suelos el sambenito de extranjerizante con que ha sido vilipendiado Feijoo, el arrojo y denuedo con que defendió a Servet y al albéitar Francisco de la Reyna, como definidores de la «Circulación menor».

Y el elogio casi frenético que dedica a Solano de Luque, hecho ya al final de su producción literaria -quinto tomo de las Cartas Eruditas. 
Dejamos aparte el mérito intrínseco de Solano, muy puesto en cuarentena por el doctor Marañón. A nosotros nos interesa destacar e1 sincero alborozo con que Feijoo acoge la noticia que desde Francia le envía, relativa al triunfo de un médico español.

"Tres años ha, y no más, que tuve la primera noticia del doctor Solano de Luque, tan desnudo entonces de todo conocimiento del sujeto, que ni su nombre había sido leído y oído jamás. Esta primera noticia debí a don Ignacio Torres, noble valenciano, que hoy está ejerciendo en París con estimación la Medicina,»

Este noble valenciano le escribe al P. Feijoo:

"De intento he nombrado el último a Solano, para celebrar con usted un español, que en sentir de los mejores médicos de nuestros tiempos.»

A continuación se lamenta Feijoo:

"Y lo que sentí saber que, mientras se vendían en España los ejemplares de la única edición de su utilísima obra, había leído ya un compendio de ellas en las lenguas latina, inglesa, francesa y alemana, a fin de dar las notas con que me decían había sido aumentada una de dichas ediciones."

Inmerecido el elogio, es probable; pero digno de consignarse, para demostración de la actitud hispana de Feijoo, siempre que hallaba ocasión para destacarla.

$\mathrm{Y}$ es que, cuando en la vida se tiene una fuerte personalidad, raro es el campo adonde aquélla no llegue. Por mi propia personalidad he hablado del P. Feijoo como Médico y como Catedrático. Si, además de la toga de Catedrático, vistiese la de jurista, tendría que hablar también de él como jurista, recordando aquella obra, Balanza de Astrea o Recta Administración de la Justicia, en la cual, simulando una carta que un togado anciano dirige a un hijo suyo, recién elevado a la judicatura, discurre sobre el tema con agudeza epigramática. Recientemente algunos Colegios de Abogados han recogido párrafos de estos dichos, y es en ellos donde Feijoo, ensalzando la Justicia y su pureza, advierte a los togados que rechacen prebendas y amistades, porque el templo de Astrea debe quedar fuera de las puertas todas.

En este ir y venir de elogios encendidos discurrió la vida del Padre Feijoo. Y casi daría por terminada esta fatigosa disertación, si no quisiera cerrarla con la alusión de dos nombres leoneses que defendieron a Feijoo con la fuerza con que pudiera defenderse entonces la combatividad de un "Paso honroso». 
Uno de estos hombres es nuestro ínclito, y nunca suficientemente ponderado, P. Isla. Para no ser tachado de leonesista ultramontano, me permito reproducir los conceptos que figuran en el tomo XV de la Biblioteca de Autores españoles, dedicado a recopilar algunas - las más principales- de las obras de nuestro punzante y divertido leonés. Firma el prólogo -estudio de dicha obra- don Pedro Felipe Monláu, en esta edición de 1876, y dice así:

«El Teatro Crítico tuvo tantos impugnadores como, treinta años después, había de tener el Fray Gerundio. El P. Feijoo se defendía enérgicamente, como treinta años después había de defenderse también el P. Isla; pero no le servía de poco la cooperación de los inteligentes que le ayudaban a anonadar a sus adversarios. Uno de estos cooperadores, celosos y desinteresados, fue el P. Isla, quien, joven entonces (17031781) - poco más de veintitrés años, nos permitimos recordar nosotros-, lleno de savia y vigor, y simpatizante con las buenas doctrinas que sembraba el esforzado P. Feijoo, esgrimió denodadamente siempre su festiva y temible pluma contra el doctor Pedro de Aquenza, contra el bachiller Diego de Torres Villarroel y contra otros varios que osaban impugnar sin razón ni gracia las obras del famoso benedictino.

"Pero qué mucho -continúa-, que entre Feijoo e Isla mediase la más estrecha simpatía, si ambos eran regulares, ambos eruditos, ambos escritores incansables e impávidos, ambos habían de ser perseguidos, ambos eran llamados a ejercer grandes influencias y representación en el siglo XviII."

Millares de Carlo y el propio Monláu citan las obras que escribió el P. Isla en defensa del P. Feijoo. Por la extensión de su título no la citamos. Son cinco y se hallan incluidas en la Colección de papeles críticos $y$ apologéticos, del $\mathrm{P}$. Isla.

Sí voy a permitirme una cita encontrada en el prólogo del Girundio de Campazas. Publicado el libro en 1758, habían cedido ya las controversias alrededor de las teorías médicas del P. Feijoo y habían hecho furor las iniciadas en 1749 por el franciscano Francisco Soto y Marne, con su libro Reflexiones crítico-apologéticas.

Pero hete aquí que, en 1746, aparece en Portugal el Verdadeiro mé todo de estudar para ser util à Republica e à Igreja, proporcionado ao estilo e necesidade de Portugal. Su autor es el acreditado Luis Antonio Verney, por seudónimo «Barbadinho".

Declara el P. Isla en el mencionado prólogo que, al ridiculizar a los oradores sagrados ridiculizables, no citarán nunca nombres, excepto a uno: El Barbadiño, a quien describe de manera feroz, dedicándole, como más suaves, la siguientes lindezas: 
JULIO MORROS SARDA

«Se le arrancan las barbas postizas, que se pegó como vejete entremés; y se le hace salir al púlpito con su cara lampiña natural o a lo menos barbi-hecha..., con su bonetico cuadrado y mocho, arrimado al pecho y sustenido con los dos dedos de la mano derecha, tan pulidamente, que no parece sino que el hombre toma bonete, como otros toman tabaco», etc.

"Se le señala con el dedo -añade más adelante-, sacándole a lucir con todos sus dictados, bien que todavía se le perdone el nombre y el apellido.»

La causa de tal distinción es la siguiente:

"¿Por qué se había de llevar la mano blanda con quien la lleva tan bronca y tan pesada con los maestros y príncipes de casi todas las facultades? ¿Quién había de tener paciencia para halagar, acariciar y quitar el sombrero, con mucha cortesía, al que se pasa con la gorra calada delante de los hombres de mayor veneración, que todos respetamos? Al reverendísimo, eruditísimo, sabio y discreto maestro y señor Feijoo le trata como pudiera a un monaguillo. $Y$ es la gracia que, en aquellos puntos en que convienen los dos, no se vale El Barbadiño de otras razones que las que trae el maestro Feijoo, sin más diferencia que esforzarlas éste con hermosura, con nervio, con eficacia y con modestia, y dejarlas caer aquél al desgaire, a lo farfantón, desdeñoso y despreciativo.»

No creemos que pueda caber mayor lealtad admirativa, por parte de un escritor de veintisiete años, y más joven que Feijoo, y perteneciente, por añadidura, a distinta Orden religiosa.

Séame permitido citar, como final, el abanderado fiel de la gloria de Feijoo, aquél que, sin tener nada que ver con la Medicina y los Médicos, merece, por servicio de lealtad, ocupar este puesto que le dedicamos. Se trata de Fray Martín Sarmiento (Pedro José García Balboa) (1695-1771), natural de Villafranca del Bierzo. Hombre de extensa y profunda cultura, amigo de los libros, proveedor de cuantas obras necesitaba el P. Feijoo; su más ferviente defensor; su colaborador más íntimo y más devoto. La sombra protectora que dio relieve definitivo a la obra feijoniana. Define Marañón:

«Todo gran hombre de verdad tiene en la sombra otro ser que le sirve y desembaraza de cuanto es menester; que le sostiene cuando decae; que, en muchas ocasiones, le inspira... Unas veces es una mujer; otras, un amigo; un simple secretario, quizá; o una organización y oficina secretas...."

Sarmiento fue un caso ejemplar de devoción, austeridad, talento, eficacia y lealtad hacia el gran amigo y superior. Grande y noble es la figura de Feijoo; grandes y nobles fueron sus amigos; fuertes y esquina- 
dos, duros de roer, algunas veces, sus enemigos, que sirvieron para aumentar su gloria. Pero afirmamos que su mayor gloria fue merecer la amistad de un hombre como Sarmiento, capaz de medir con toda exactitud todo cuanto merecía de fiel colaboración el ilustre Padre Maestro.

Sarmiento no sólo merece ser destacado al discriminar el papel que Feijoo representó frente a la Medicina y los Médicos de su tiempo, sino en la actividad entera feijoniana. Y bueno es que, al levantar el nombre del benedictino ilustre, nuestra voz llegue al amigo que, en la discreta sombra de un segundo plano, fue el sólido y constante sostén de la obra.

De una obra de tanta mayor valoración cuanto más sencillamente la calificaba Feijoo:

«No se me considere como un atrevido ciudadano de la República Literaria que, satisfecho de las propias fuerzas y usando de ellas, quiero reformar su gobierno; sino como un individuo celoso que ante los legítimos ministros de la Enseñanza Pública, comparece a proponer lo que le parece más conveniente, con el ánimo de rendirse en todo y por todo a su autoridad y juicio.n

Palabras con las que, por imperativo categórico de su austera dignidad, debo dar por terminada la presente disertación.

\section{B I B L I O G R A F I A S}

Anónimo: Disputas médicas. Feijoo y el doctor Martinez.

Araujo Costa, L.: Letras, damas y pinturas, Madrid, 1927.

Azorin: Los valores literarios, 1913.

Castillo de Lucas: «El Padre Feijoo y la Medicina popular, en Yatros, XIX, núm. 537 (de 5-1-65), pág. 17, Oviedo.

Entrambasaguas, J. de: Antología de Feijoo, Madrid, 1942.

Feijod, B. J.: Teatro Crítico Universal, ocho tomos, edición Ibarra, Madrid, 1783.

Feijoo, B. J.: Cartas eruditas, cinco tomos, edición Román, Madrid, 1781.

Feijoo, B. J.: Suplemento al Teatro Crítico o Adiciones y correcciones a muchos de los asuntos que se tratan en los ocho de dicho Teatro, Madrid, 1740.

Feijoo, B. J.: Justa repulsa de inicuas acusaciones. Carta en que manifiesta las imposturas que contra el Teatro Critico y su autor dio al publico el R. P. Francisco Soto Marne, escribe a un amigo suyo el P. P. M. D. ........., Madrid, 1749.

Feijoo, B. J.: Ilustración apologética al primero y segundo tomo del Teatro Crítico Universal, donde se notan más de cuatrocientos descuidos al autor del Antiteatro, y de los setenta que éste impugna al autor del Teatro Critico se rebajan sesenta y nueve y medio, Madrid, 1729. 


\section{JULIO MORROS SARDA}

Flórez, P.: Aprobación del tomo segundo de Cartas eruditas.

Hurtado Jiménez de la Ser, J., y González Palencia, A.: Historia de la literatura, Ed. S. A. E. T. A., 6.a edición, Madrid, 1949.

Isla, Padre J. F.: Colección de papeles crltico-apologéticos que en su juventud escribió el Madrid, 1788.

Isla, Padre J. F.: Obras, Biblioteca de Autores Españoles, t. XV, Madrid, 1876.

Junceda Avello, E.: El saber ginecológico del Padre Feijoo. Instituto de Estudios Asturianos. Imprenta «La Cruz», Oviedo, 1964.

Lafuente: Obras escogidas del P. Feijoo, t. LVI de la B. A. E., Madrid.

Mañer, Salvador José: Anti-teatro Crítico. Sobre el primero y segundo tomo del Teat,o Critico Universal, Madrid, 1730.

Marañón, G.: Las ideas biológicas del Padre Feijoo,, tercera edición. Editorial Espasa-Calpe, S. A. Madrid, 1954.

Marañón, G.: Evolución de la gloria de Feijoo. En Cuadernos de la Catedra Feijoo, Universidad de Oviedo, 1955.

Maranón, G.: Efemérides y Comentarios. Inauguración en Oviedo de una estatua al Padre Feijoo, Editorial Espasa-Calpe, S. A., Madrid, 1955.

Marañón, G.: Tiempo vicjo y tiempo nievo, octava edición. Colección Austral (t. 140). Editorial Espasa-Calpe, S. A., Madrid, 1960.

Marañón, G.: Vida e Historia, octava edición. Colección Austral (t. 185). Editorial Espasa-Calpe, S. A., Madrid, 1962.

Marañón, G.: La Medicina y nuestro tiempo, tercera edición. Colección Austral (t. 1201). Editorial Espasa-Calpe, S. A., Madrid, 1963.

Marqués y Espejo, A.: Diccionario Feijoniano, Madrid, 1802.

Martínez, Martín: Carta defensiva que sobre el primer tomo del Teatro Crítico Universal que dio a luz el Rmo. P. Maestro Fray Benito Feijoo la escribió su más aficionado amigo don Martín Martínez (incluida en el tomo segundo del Teatro Crítico Universal, del Padre Feijoo).

Martínez, Martín: Medicina Scéptica y Cirugía Moderna con un tratado de Operaciones, etc., Madrid, 3.a edición, 1748. (Contiene también del Padre Feijoo, al priticipio, «Aprobación apologétía del scepticismo médico del doctor Martín Martínez». Oviedo, 1725.)

Menéndez Pelayo, M.: La Ciencia Española, Madrid, 1876.

Menéndez Pelayo, M.: Historia de los Heterodoxos españoles, Madrid, 1880.

Millares Carlo, A.: Antología del Padre Feijoo. Prólogo de "Clásicos Castellanos». Madrid, 1923.

Monláu, P. F.: Prólogo a la Antología del Padre Isla.

Morros Sardá, Julio: Evolución del experimentalismo en las Ciencias Biológicas, discurso inaugural del curso académico 1956-57. Universidad de Oviedo, 1956.

Pardo Bazán, E.: Estudio crítico de las obras del P. Feijoo, Madrid, 1877.

Pérez, Fray José: Aprobación del tomo sexto del Tealro Crítico, 1734.

Salgado Benavides, Félix: La Medicina Sacerdotal a través de la Historia. Págs. 201 a 246, Apéndice, Et Padre Feijoo. Asociación Española de Médicos, Escritores y Artistas. Primer premio concurso "Blanco Solern; Madrid, 1958-59.

Sarmiento, Padre Martín: Demostración crítico-apologética del Teatro Critico Universal, dos tomos, segunda edición (reimpresión). Madrid, 1739.

Soto y Marne, Francisco de: Reflexiones critico-apologéticas sobre las obras del R. P. Maestro Fr. Berito Jerónimo Feijoo, Salamanca, 1748.

Torres Villarroel, Diego de: Post-Datas de Torres a Martinez en la respuesta a don Juan Barroso. Sobre la carta defensiva que escribió al Ramo. Fray Bcnito Feijoo, y en ella se explica el camino det globo de luz o fenómeno que apareció en nuestros horizontes el 19 de octubre de este año de 1726, Salamanca, 1729.

Vila Selma, J.: Antologia de Feijoo, Madrid, 1963. 